\title{
The Elephant Problem in the Serengeti
}

Elephants have come into the Serengeti National Park in the last ten years, and are now doing considerable damage. In an appendix to his Report (see page 398), from which these extracts are taken, Professor Russell discusses this problem and makes recommendations for dealing with it. The appendix discusses management problems in each of the five Tanzanian national parks - Arusha, Mikumi, Ruaha, Lake Manyara and Serengeti, in the last case with particular reference not only to the elephants but also to the size of the migratory wildebeest and zebra herds and the influence of the tourists.

CROM a vegetational point of view the Serengeti consists of extensive grass plains which extend into the Ngorongoro Conservation Authority area and the Loliondo grazing areas in the south-east and east, and wooded grassland to the north and west. The open grassland is largely on volcanic ash soils and the wooded grassland on soils derived from granitic or basement rocks. The outstanding features of the park are the very large herds of migratory wildebeest and zebra, which spend the wet season on the short grass plains and migrate into the northern part of the park in the dry season. But during the last decade this part has begun to suffer a major change in vegetation due to the sudden entry of elephants from Kenya, which have been killing or knocking over such a large number of trees that in some areas woodland has been converted to grassland. This damage is so striking that it has become urgently necessary to decide if any action should be taken against the elephant so as to maintain an adequate a rea of woodland for the benefit of animal species that live in it and for the benefit of the visitors who come to the park. I believe it is accepted as fact that:

1. elephants have only recently entered the park after a long absence from it which has been for at least 40 years and may have been very much longer; [see Note on page $390-$ Editor];

2. the park contains very little of the typical habitats preferred by elephants;

3. since the elephants have entered the park they have caused a very great decrease in the number of tall trees in several parts of the park, and in some places have converted well-wooded acacia grassland into almost treeless grassland. They have also caused a rapid destruction of large mature Acacia xanthophloea trees along some of the watercourses.

Before the Trustees can take any decision of what to do about the consequences of this influx into the park, they need answers to the following questions:

a. how important, from the point of view of achieving the goals of the Serengeti, is this rapid destruction of trees?

$b$. if it is important, can it be reduced to an acceptable level by reducing the numbers of elephants in the park?

c. if so, how many elephants, and of what age and sex, need to be killed or removed? 


\section{Plate 4}

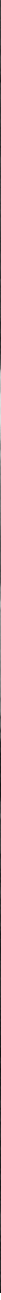

IS HE A VILLAIN?

Norman Myers 


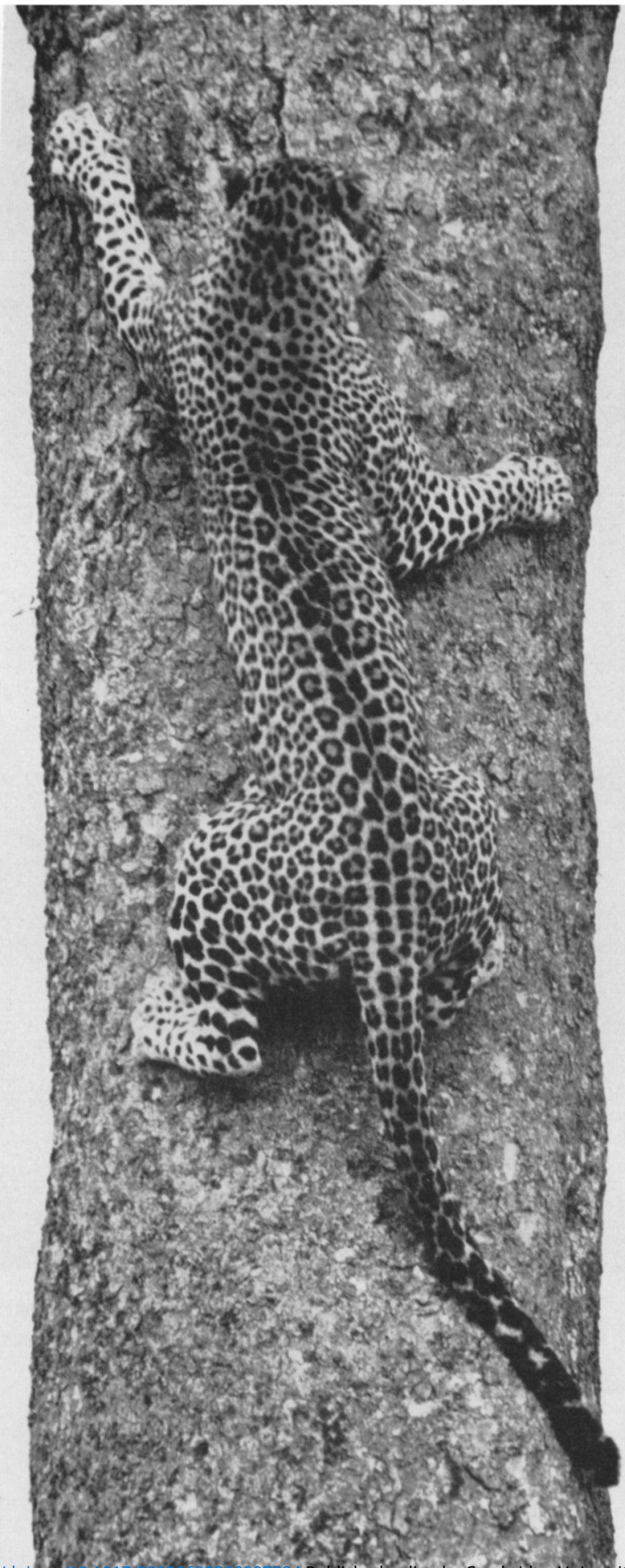

Plates 5 and 6

LEOPARD'S WAY

UP ...

... TO A NICE

SIESTA

Norman Myers 


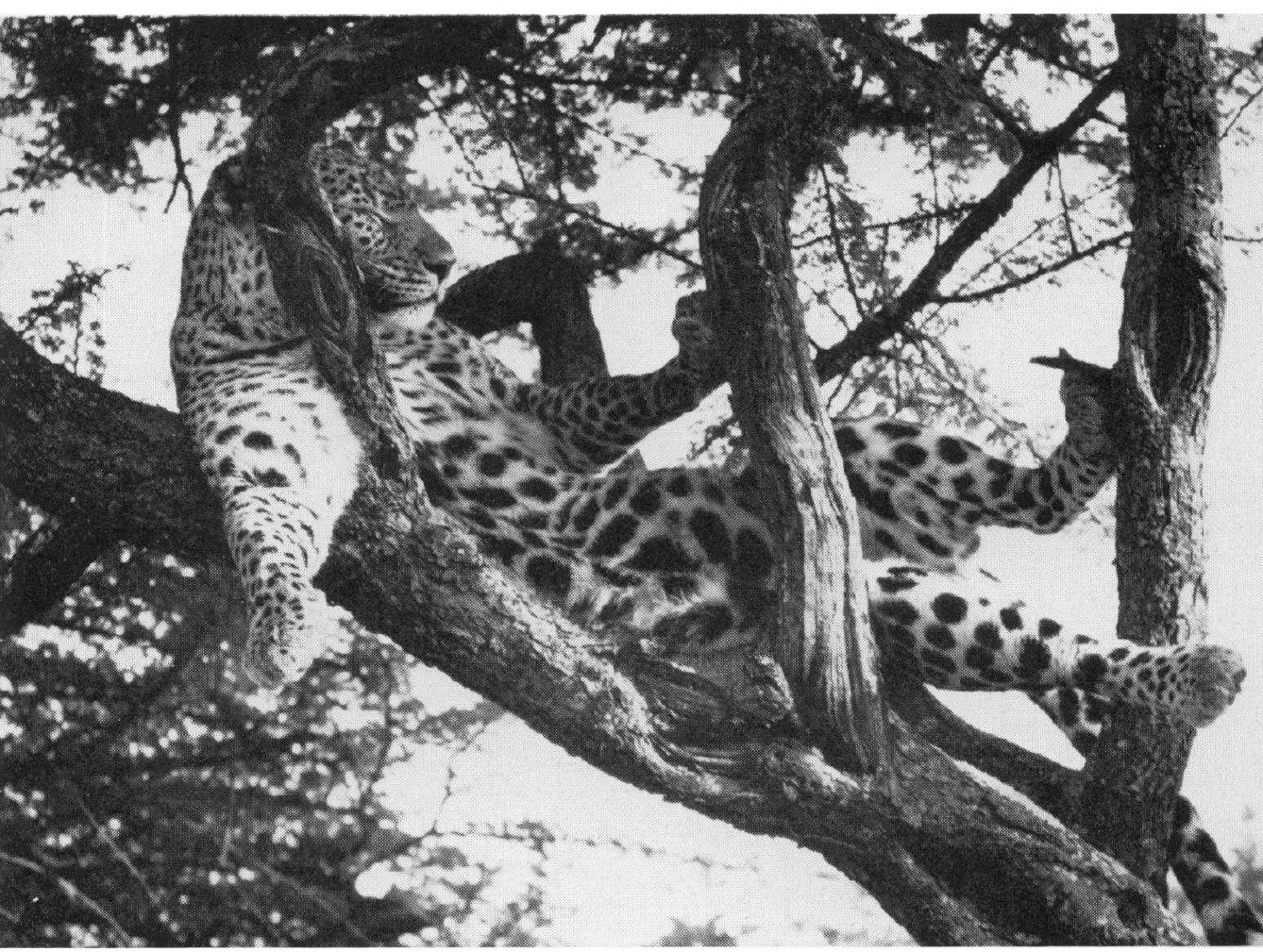




\section{Plate 7}

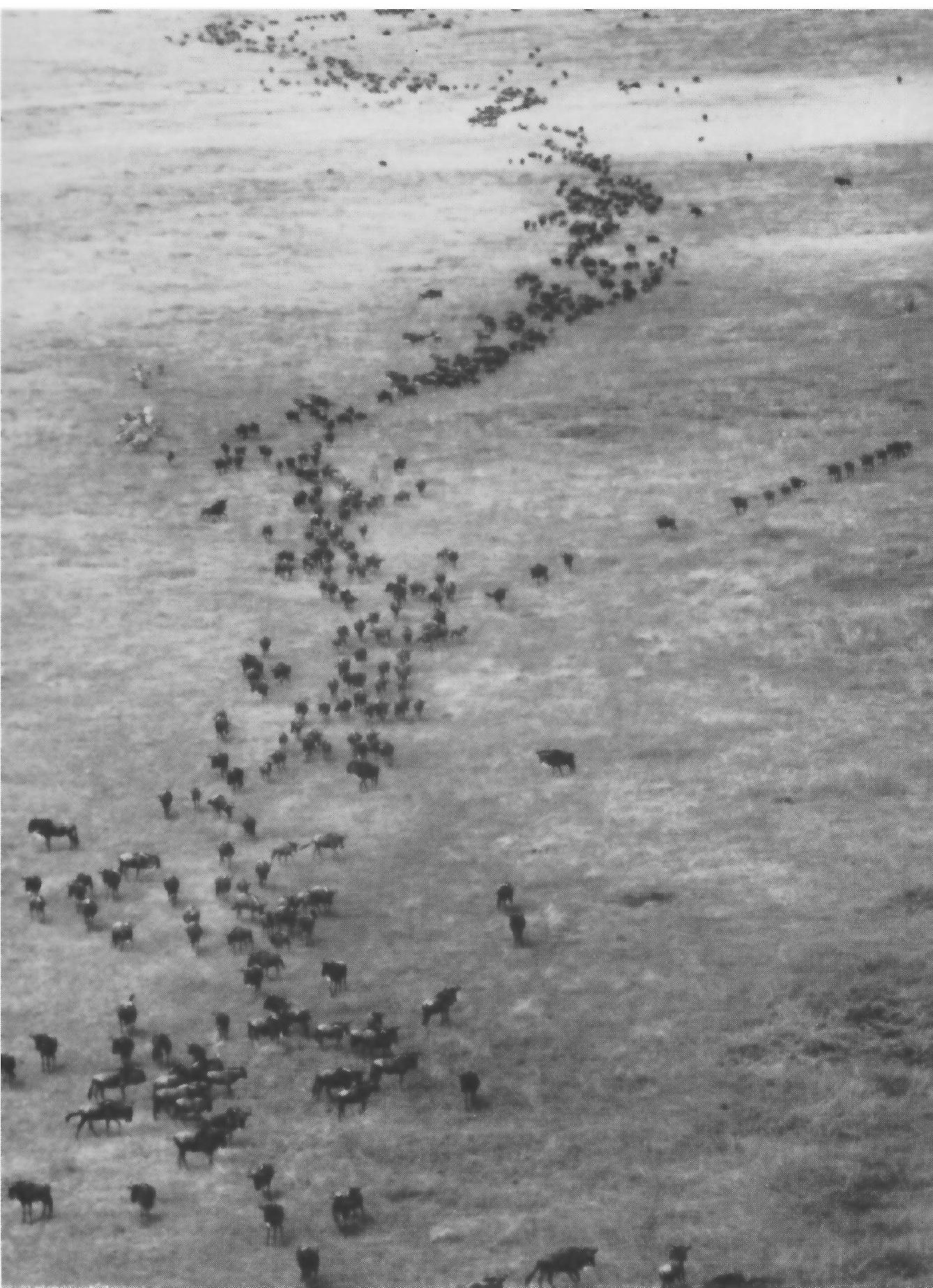

WILDEBEEST MIGRATION IN THE SERENGETI 
$d$. in any case, are any elephants wanted, seeing that they have been in the park for a bare ten years?

The last question is a pure policy decision, and I will assume that it is agreed that elephant should stay in the park, because if it is agreed they should all be removed, the earlier questions become irrelevant.

The principal wooded areas in the Serengeti are in the northern parts and they carry a very considerable number of animals that require trees. These include the roan antelope, a species rare in Kenya and Northern Tanzania, impala and oribi which need woodland, the eland and buffalo which need woodland at some times of the year, and the giraffe whose fodder is primarily acacia trees and bushes. Thus there is a very strong case for maintaining considerable areas of woodland for the preservation of reasonable numbers of these species; and this is particularly true in the Serengeti because it already contains very large areas of treeless grass plains. But in many of the areas where the elephants are causing a major change in the habitat, most of the trees are mature or overmature, so will not last for many more years, and there are few trees of intermediate size, so once these older trees have gone, the areas will become open grassland. Thus, removal of the elephant will not be sufficient to maintain these areas as wooded grassland in a few years time under present conditions.

This raises the question of how this wooded grassland came into being, and why it is not regenerating as woodland. The reason it is not regenerating appears to be that the grass gets burnt every dry season and the fire is hot enough to burn back the annual growth of the acacia. In some areas the grass contains many small acacia plants with very well developed root systems, showing that the plant is old, but it is dwarfed and stunted by the annual burn. If fire is kept out of this land, possibly for as little as two years, the plant will grow tall enough to allow it to withstand the grass fires. On this picture, the old trees grew up when for some reason there was a period of several years without grass fires, and it is tempting to think that this coincided with the severe outbreaks of smallpox and rinderpest which decimated the Masai and their herds at the end of the last century.

It is therefore possible that the elephant is only hastening by 10-20 years the conversion of much of the wooded grassland into open grassland. On the other hand if active management can reduce the incidence of fire, it is a matter for research to establish if enough of these older trees would remain alive to allow the regeneration to become sufficiently advanced for it to be an acceptable habitat for the woodland game species. Thus, it is not yet possible to give a proven answer to the question of whether destruction of part of the elephant herd would allow an appreciable area of wooded grassland to be maintained for these woodland game species during the next three decades.

Elephant damage in the park is of two kinds. First, a proportion of the tall mature acacia trees, principally tortilis, clavigera and xanthophloea, are being knocked down and some of these do not seem to have been eaten. This knocking down and not feeding on the tree appears to be done by bulls in their middle age, possibly a behavioural pattern due to the 
disturbances they have lived through before entering the park. Second, feeding elephants, including cow herds, kill trees of these species, particularly the first two, by debarking or by the breaking of branches or the tree trunk. Further, all elephants will feed on regenerating trees and prevent them growing into trees at all and particularly into the very attractive shapes characteristic of these species when undamaged. However, regeneration may give a thicket of young acacia trees, and elephants may be the most efficient way of thinning out the thicket and allowing some trees to become emergent and develop their characteristic crown.

The destruction of the mature trees could probably be lessened by reducing the number of the mature bulls appreciably, but this might have the consequence of increasing the conception rate of the cow herds, if it is below the maximum rate. The present elephant population in the woodland and parkland areas is probably just over one per square mile, which is probably about twice the maximum density the present vegetation can sustain without appreciable deterioration of the parkland habitat. Thus any increase in the reproductive rate of the cow herds could lead to a still more rapid disappearance of this habitat.

Coming down to detailed proposals, I consider it very urgent that the Trustees be furnished with the following information to help them decide on what action to take, if they wish to retain sufficient woodland and parkland to maintain reasonably sized herds of the principal woodland species, if this turns out to be a possible policy.

1. An estimate should be made of the minimum requirements of the woodland species as far as size of tree is concerned, and of the number of years it is likely to take a seedling or existing fire-dwarfed tree to reach this size.

2. On the basis of this estimate, a further estimate should be made of the areas that can reasonably be expected to remain or to become a suitable habitat for these species decade by decade, for the next 20-30 years, if all elephants were removed and fires were controlled. It is not necessary that the same patch of country remains woodland, it is merely necessary that if a patch that was wooded becomes open grassland an equivalent area of open grassland becomes wooded, through regeneration of trees.

I am aware that these estimates will be subject to large margins of uncertainty, but they should indicate if there is an a priori case for reducing elephant populations to allow for the maintenance of acceptable populations of the woodland species. If these estimates show that under these assumptions, acceptable areas of woodland cannot be maintained, elephant control will obviously be powerless to prevent this loss of woodland habitat; but if it shows that it could be maintained in the absence of elephants, calculations can then be made of the number of trees that can be killed each year whilst maintaining an adequate area of habitat, and of the number of elephant that can be allowed if this rate is not to be exceeded. I would recommend that this work be put in hand immediately as a matter of urgency so that a preliminary answer to the question of whether any elephant should be killed can be given in three to five years. 